\title{
Impacts of Cultivated Land Reclamation on the Climate and Grain Production in Northeast China in the Future 30 Years
}

\author{
Qingling Shi, ${ }^{1,2}$ Yingzhi Lin, ${ }^{3}$ Enpei Zhang, ${ }^{3}$ Haiming Yan, ${ }^{4}$ and Jinyan Zhan ${ }^{4}$ \\ ${ }^{1}$ Institute of Geographic and Natural Resources Research, Chinese Academy of Sciences, Beijing 100101, China \\ ${ }^{2}$ Center for Chinese Agricultural Policy, Chinese Academy of Sciences, Beijing 100101, China \\ ${ }^{3}$ School of Mathematics and Physics, China University of Geosciences (Wuhan), Wuhan 430074, China \\ ${ }^{4}$ State Key Laboratory of Water Environment Simulation, School of Environment, Beijing Normal University, Beijing 100875, China \\ Correspondence should be addressed to Jinyan Zhan; zhanjy@bnu.edu.cn
}

Received 8 July 2013; Accepted 28 August 2013

Academic Editor: Xiangzheng Deng

Copyright (c) 2013 Qingling Shi et al. This is an open access article distributed under the Creative Commons Attribution License, which permits unrestricted use, distribution, and reproduction in any medium, provided the original work is properly cited.

\begin{abstract}
China, as a large agricultural country as well as a major country with great demand for grain, has played a more and more important role in the international grain market. As Northeast China is one of the major commodity grain bases in China as well as one of the regions with the highest intensity of human activities, it plays an important role in influencing the global food security. This study first generally analyzed the cultivated land reclamation and the climate change of temperature and precipitation in Northeast China during 2000-2010. Then, on the basis of these data, the climatic effects of cultivated land reclamation in Northeast China during 2030-2040 were simulated by the weather research forecast (WRF) model. Finally, the possible effects of the climate change on the grain yield and the potential influence on the food security were analyzed. The simulation result indicated that the temperature in Northeast China would be increasing on the whole, while the precipitation would be decreasing. The result of this study can provide some theoretical support to the agricultural economic development in Northeast China and serve the national macropolicy and food security strategy of the whole China.
\end{abstract}

\section{Introduction}

Northeast China as an important commodity grain production base in China plays an important role in guaranteeing the global food security, while the historical large-scale cultivated land reclamation is of great importance to the formation and development of this commodity grain production base. Northeast China currently provides 30-35 million tons of grain every year, accounting for $13 \%$ of the national total grain output [1]. Besides, China being a large agricultural country, as well as a major country with great demand for grain, plays a very important role in the international grain market. According to the Medium and Long Term Planning Outline of National Food Security (2008-2020), the grain output of China will have reached 545 billion $\mathrm{kg}$ by 2020 . Northeast China as the core region of grain production of China will undertake the tasks of making the grain output increase by 15.05 billion $\mathrm{kg}$, which will account for $30.1 \%$ of the newly increased grain output. Therefore, the grain production in
Northeast China will have great impacts on the Asian and even the global food security $[2,3]$.

The cultivated land reclamation in Northeast China has lasted for many years since the last century due to the continual population growth and economic development at the cost of large-scale overconsumption of resources [4]. As a result, the frequent and uneven occupation and reclamation of cultivated land have led to the significant dynamic change of the spatial pattern of cultivated land in Northeast China. Except for the restriction of the cultivated land area, the grain production in Northeast China is also influenced by the climate change. The heat resource during the growth season of crops has shown an increasing trend in Northeast China, and the temperature has increased significantly in the past decades. For example, the relevant research indicates that the temperature in Northeast China has increased by $1.43^{\circ} \mathrm{C}$ in the past century [5], which is 2 times higher than the global average level and 3 times higher than the national average level. The rapid temperature rise will surely have significant 
impacts on the growth of crops [6]. It has been widely accepted that the climate change is influenced by the human activities $[7,8]$, and the land use change, as one of the major approaches through which the human activities influence the climate change, has received more and more attention [9]. The change of the spatial pattern of cultivated land in Northeast China will surely lead to climate change at local and regional scales. The historical data indicate that along with the cultivated land reclamation, there has been significant climate change in Northeast China, including the obvious change of the spatial pattern of temperature and precipitation [10]. In addition, the relevant researches also indicate that there is close correlation between the significant climate change and the more and more large-scale cultivated land reclamation in Northeast China in recent decades [11-14]. It will surely contribute to the more comprehensive understanding of the land surface change to analyze the interaction between the cultivated land reclamation and climate change and to assess its impacts on the regional grain production.

So far, there are plenty of researches for climatic prediction in many research fields around the world. But most of them have disadvantages [15]. Some of the previous studies predict the climate change in future just simply according to the history climate data and their variation trend [1618]. It is well known that there is uncertainty in climate change and that abnormal climate always occurs especially in recent decades, which made the history trend unreliable to represent the real one. Therefore, the shortage of this method was obvious. For that reason, some scientists began to predict future climate with models [19-21]. This was a great improvement in the process of the prediction research. But there were still disadvantages in the studies. With various kinds of models, different prediction results in the same simulated region have always been reported; sometimes these results were even contradictory, while the Weather Research and Forecast (WRF) model used in this study is a next-generation mesoscale numerical weather prediction system developed by a group of scientists from different institutes. This model is of strong robustness for predicting the climate change with various kinds of parameters, such as temperature, precipitation, radiation and heat. What is more, in this study, is that the underlying surface data used in WRF model was the simulated data with DLS model instead of the other scenarios, which was different from other prediction models. Thus, this study is of great significance both to the method building and its application.

\section{Data and Methodology}

2.1. Study Area. Northeast China (located between $115^{\circ} 05^{\prime}$ $135^{\circ} 02^{\prime} \mathrm{E}, 38^{\circ} 40^{\prime} \sim 53^{\circ} 34^{\prime} \mathrm{N}$ ) has a total land area of 1.24 million $\mathrm{km}^{2}$ and covers 209 counties in Heilongjiang Province, Jilin Province, Liaoning Province, and Inner Mongolia Autonomous Region (Figure 1). It is the largest production area of corn, high quality japonica rice, and soybean as well as the major production base of agriculture, forestry, animal husbandry, and industry in China. The total cultivated land area in this area is approximately 227 million ha, accounting for $18.5 \%$ of the national cultivated land area. The area under

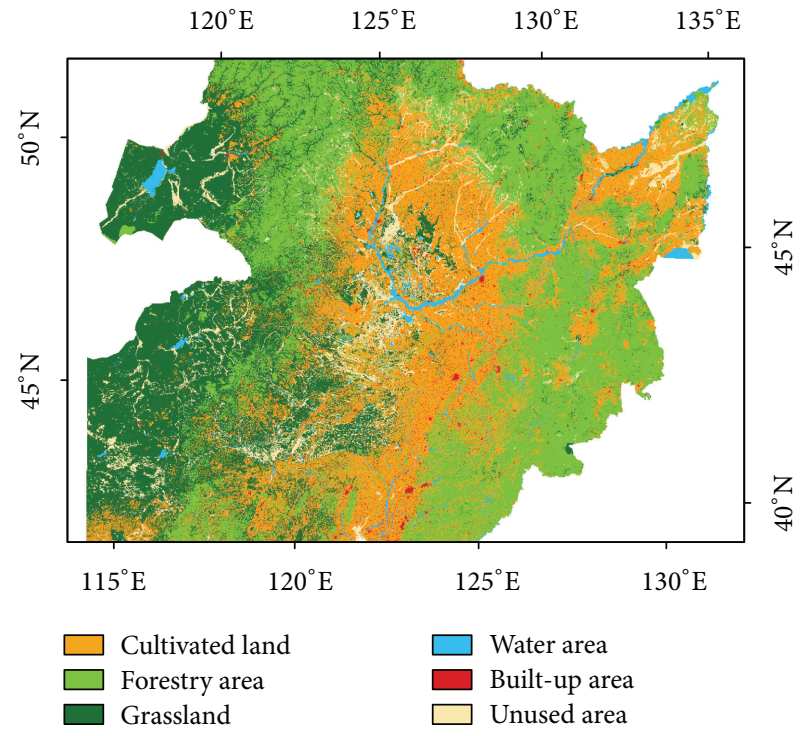

FIGURE 1: Administrative regions of Northeast China in 2010.

crops is approximately 173 million ha and the total grain output is approximately 87 million $\mathrm{t}$ in Northeast China, which account for $16.4 \%$ and $17.6 \%$ of the national total amount, respectively.

As a monsoon climate of medium latitudes, the amount of precipitation in Northeast China decreases from the east and southeast to the west and northwest on the whole area. The winter is cold and long, while there are frequent winds and little rainfall in the spring in Northeast China. In the summer, the temperature is high and the rainfall is very rich; the amounts of precipitation range from $400 \mathrm{~mm}$ to $700 \mathrm{~mm}$ in most part of Northeast China in the summer, accounting for $50 \%-70 \%$ of the annual precipitation. According to the observation data of climate change from 20002010, we calculated the change trend of temperature and precipitation in Northeast China. The results showed that the temperature increased slightly in the decade and the average growth rate per annum was $0.44 \%$. While the average annual precipitation was in a similar circumstance, its average growth rate per annum was $1.16 \%$. There are often sunny days and the southwest winds prevail in the autumn, but the amount of precipitation is slightly more than in the spring. Northeast China is the coldest area in China since it is at the high altitudes; the temperature in this region is very low in the winter and the annual temperature difference is very large, showing obvious characteristics of the continental climate. Besides, Northeast China can be divided into three climatic zones from north to south, that is, the cold temperate zone, cool temperate zone, and warm temperate zone, since it extends across a wide latitude and longitude. In addition, it can be further divided into several climatic zones from east to west, that is, Three River Plain Humid climate zone, Lesser Khingan Mountains climate zone, Great Khingan Mountains Subhumid climate zone, Songliao Plain Subhumid climate zone, and West Liaohe Plain and Eastern Inner Mongolia Arid climate zone. 
TABLE 1: Schemes of the simulation test with WRF model.

\begin{tabular}{lccc}
\hline Test & Test period & Underlying surface data & Climate forcing data \\
\hline Control test & $2000.01-2010.12$ & Land cover data of 2010 & Climate forcing data between 2000.01 and 2010.12 \\
Sensitivity test & $2030.01-2040.12$ & Land cover data of 2040 & Climate forcing data between 2000.01 and 2010.12 \\
\hline
\end{tabular}

Northeast China is the optimal grain production area with great development potential, and it plays an important role in guaranteeing the national food security. Most part of the Northeast Plain and the valleys and tablelands between Changbai Mountains has been reclaimed for cultivated land so far. These regions have been the major agricultural areas in Northeast China, but at the cost of the disappearance of primary forests and grasslands. The scale of grain production is very large, and the major crops include corn, soybean, and rice. The level of agricultural mechanization is very high in Northeast China since it is one of the regions with the earliest agricultural mechanization and the best basic conditions in China. What is more is that Northeast China is the largest forest area in China. The total forest area in Northeast China reaches 6 billion $\mathrm{km}^{2}$, accounting for $28.1 \%$ of the national forest area, and the close forest area is 3.34 billion $\mathrm{km}^{2}$.

This study analyzed the impacts on the climate change of cultivated land reclamation by analyzing the change of temperature and precipitation numerically predicted with the Weather Research Forecast (WRF) model on the basis of cultivated land change in 30 years in Northeast China which was simulated by the Dynamics of Land System (DLS) model in a previous study $[22,23]$. The changing trend of the climate in the future was predicted in the context of the change of the spatial pattern of cultivated land, and the impacts of the climate change on grain production were also analyzed. This study will not only provide a typical case study to the research on the global climate change but also provide some reference for the development of social industry structure.

Meanwhile, the trend of climate change and regional climate effects of LUCC in Northeast China indicate that there will be more complex and significant climate change in Northeast China, which means that the change trends of temperature and precipitation were not simply increasing or decreasing by year, they were up and down and what is more is that they showed different tendencies in different seasons. So, it is of great significance to study the impacts of cultivated land reclamation on the climate and the grain production in Northeast China, and the results can provide significant technical support and policy suggestions for the development of Northeast China.

2.2. WRF Model and Experiment Design. The WRF model is a next-generation mesoscale numerical weather prediction system developed by a group of scientists from different institutes. The effort to develop WRF began in 1997 and was a collaborative partnership principally among the National Center for Atmospheric Research (NCAR), the National Oceanic and Atmospheric Administration, the Air Force Weather Agency (AFWA), the Naval Research Laboratory, the University of Oklahoma, and the Federal Aviation Administration (FAA). There are two dynamical core versions of WRF, that is, the Advanced Research WRF (ARW) and the WRFNMM (NMM); this study has adopted the former one in view of the research aim of this study. The ARW module includes the Preprocessing System (WPS), main program and postprocessor, and the Postprocessing System, and it provides many physics parameterization schemes. In order to simulate the temporal regional climate change, the CAM3 scheme has been used as the radiation scheme. In addition, the ocean temperature and soil temperature in the deeper layer were updated by season.

In order to draw the impact on climate change of cultivated reclamation, two simulated tests were designed in this study, a control test and a sensitivity test (Table 1). The two sets of tests both used the climate forcing data between January of 2000 and December of 2010, and the difference between them was the underlying surface data. In the control test, the test period was from January of 2000 to December of 2010. The land cover data of 2000 was used as underlying surface data in the test. As to sensitivity, its test period was from January of 2030 to December of 2040, and with land cover data of 2040 as its underlying surface data. The experiment was designed like this to avoid the influence of forcing data and simultaneously to focus the impact of land use change specially the cultivated land reclamation on the climate variation. Thereby, the effect on grain production of the reclamation of cultivated land in Northeast China would be uncovered in this study.

2.3. Data and Processing. The input data of the WRF model mainly include the underlying surface data and the climate forcing data. Part of the underlying surface data were provided by the Data Center for Resources and Environmental Sciences and the Chinese Academy of Sciences (CAS), and the rest of surface data needed in WRF were simulated by DLS model. As to the climate forcing data, they were obtained from the NCEP FNL (Final) Operational Global Analysis data.

As the simulation time was January of 2000 to December of 2010 and January of 2030 to December of 2040, the underlying surface data used in this study were the land use/cover data in 2010 and 2040 as mentioned in the experiment design section. The former period of data was the real land use/cover data provided by the Data Center for Resources and Environmental Sciences, CAS. And the latter data was simulated by DLS model with the land use/cover data of $1 \mathrm{~km}$ resolution in 1985, 1995, 2000, and 2005 as its simulated initial year data. The data of four time periods were obtained from the Data Center for Resources and Environmental Sciences, CAS. The database is constructed from remote sensing digital images by the US Landsat TM/ETM satellite with a spatial resolution of 30 by 30 meters [24]. According to the simulated results, the cultivated land reclamation data during 2030-2040 were 


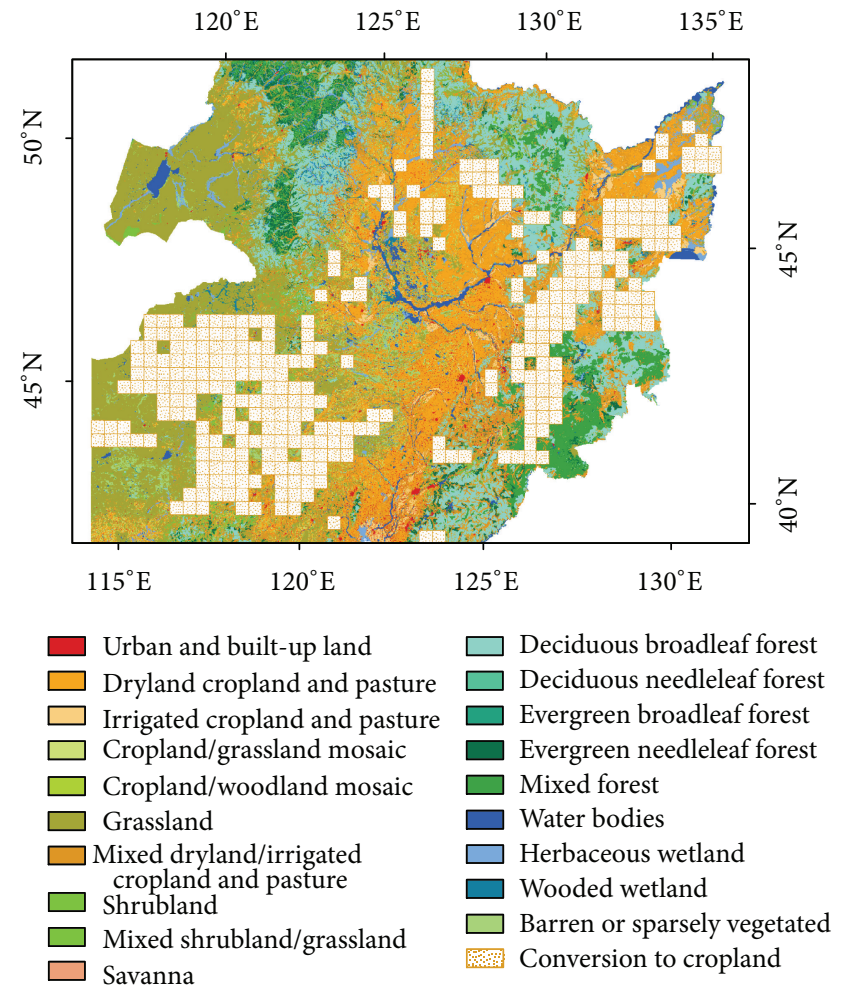

FIGURE 2: Conversion amount of other land use types into cultivated land in Northeast China during 2030-2040.

obtained in Northeast China (Figure 2) [22, 23]. According to the simulation results with the DLS model, the cultivated land area in Northeast China will increase by 288 thousand $\mathrm{km}^{2}$ during 2030-2040, with an increment rate of $21.62 \%$. The newly increased cultivated land will mainly be located in the eastern part of Three River Plain, western part of the Songnen Plain, Hilly and mountainous areas in the Great Khingan Mountains and Lesser Khingan Mountains, and Hulunbuir Region. Besides, the newly increased cultivated land will be mainly converted from the forests, grasslands, and unused land $[22,23]$.

The land use/cover data classification mechanism in WRF model was the USGS classification system (Table 2), while the simulated land use/cover data in 2040 with DLS model were classified by the land cover classification of IGBP. So the simulated data were reclassified into USGS classification system with classifier we developed before. In addition, the scale of these data is $1: 100000$, and the interpretation accuracy exceeds $92 \%$ [25].

The climate forcing data used in this study were the geographically segmented (GEOG) data obtained from NCEP FNL (Final) Operational Global Analysis data, which was updated every 6 hours. This dataset has been constructed and updated since July 1999 with the data assimilation of almost all kinds of observation data (e.g., the remote sensing data and ground-based observation data); it has the spatial resolution of $1^{\circ} \times 1^{\circ}$ and the vertical height of 27 layers. And the time periods of the data were truncated from January 2000 to
TABLE 2: Land use/cover types of the USGS classification system.

\begin{tabular}{ll}
\hline Value & Description \\
\hline 1 & Urban and built-up land \\
2 & Dryland cropland and pasture \\
3 & Irrigated cropland and pasture \\
4 & Mixed dryland/irrigated cropland and pasture \\
5 & Cropland/grassland mosaic \\
6 & Cropland/woodland mosaic \\
7 & Grassland \\
8 & Shrubland \\
9 & Mixed shrubland/grassland \\
10 & Savanna \\
11 & Deciduous broadleaf forest \\
12 & Deciduous needle leaf forest \\
13 & Evergreen broadleaf forest \\
14 & Evergreen needleleaf forest \\
15 & Mixed forest \\
16 & Water bodies \\
17 & Herbaceous wetland \\
18 & Wooded wetland \\
19 & Barren or sparsely vegetated \\
20 & Herbaceous tundra \\
21 & Wooded tundra \\
22 & Mixed tundra \\
23 & Bare ground tundra \\
24 & Snow or ice \\
99 & Interrupted areas (goode homolosine projection) \\
100 & Missing data \\
\hline &
\end{tabular}

December 2010. Then the climate forcing data were prepared on the basis of these data. The NCEP/FNL dataset has higher accuracy and spatial resolution and includes more kinds of environmental variables than the datasets of NCEP I, NCEP II, and EAR40. This study has used the Noah land surface parameterization scheme, with which the simulation result is more stable and reasonable. The data of the temperature field and precipitation field in this scheme were interpolated with the large-scale information.

\section{Results}

The change of cultivated land in Northeast China is directly caused by the human activities in the context of the special regional geographical conditions, such as the plentiness of the complex mountains in this region. The population growth is the fundamental reason for the expansion of cultivated land in Northeast China; the economic development is an important human driving factor, and the macro policy is also one of the driving factors of the land use change. With the continual population growth and rapid economic development in Northeast China, there will be more demand for the land resources, which will surely lead to the change of the amount, structure, mode, and intensity of land use. It is forecasted that the population of China will rise to the peak 


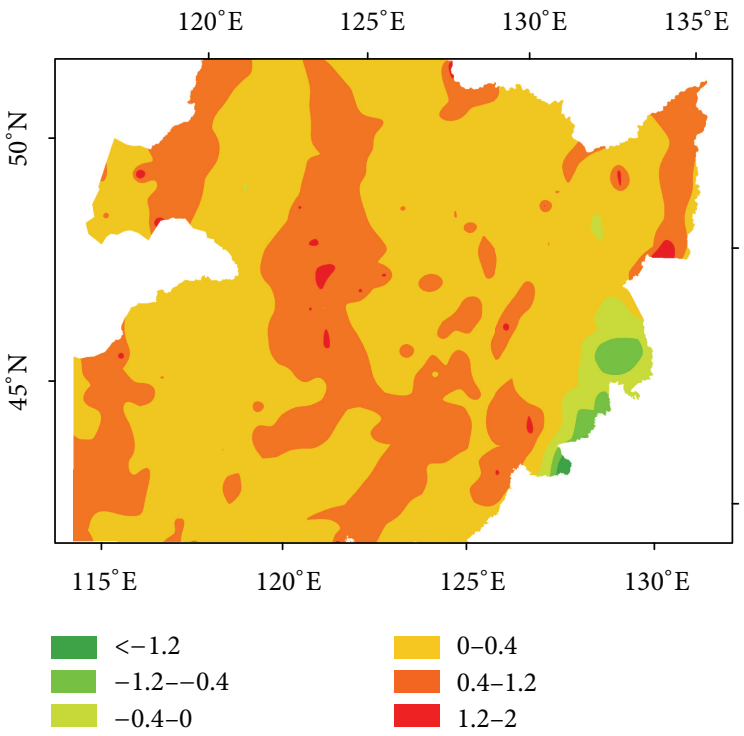

(a)

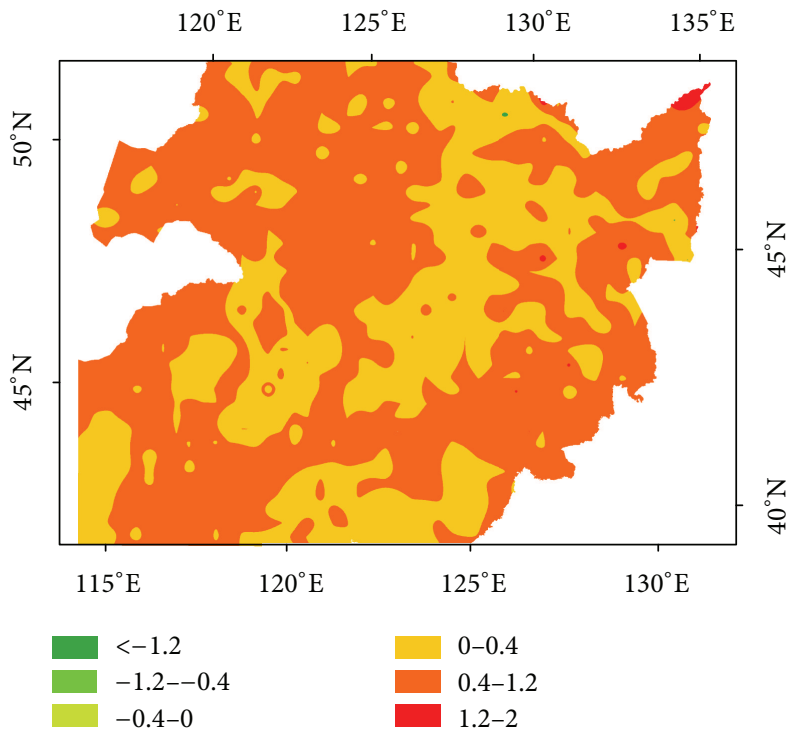

(b)

FIGURE 3: Temperature change in Northeast China in (December, January, and February) DJF (a) and (June, July, and August) JJA (b) during 2030-2040.

during 2030-2040, reaching 1.5-1.6 billion. The cultivated land area in China will certainly be increased so as to meet the enormous demand of the large population for grain, forage, dairy products, and so forth. It is inevitable that a lot of land will be reclaimed for cultivated land reclamation in Northeast China since it is the most important commodity grain base with the greatest development potential in China. For these reasons, this study simulated the climate change under the condition of cultivated land reclamation during 2030-2040 based on the WRF model and predicted the future changing trend of the temperature and precipitation in Northeast China. The simulation results indicate that the temperature in Northeast China will show an increasing trend, while the precipitation will show a decreasing trend. The average temperature in Northeast China shows an increasing trend on the whole during the simulation period. The temperature will increase in most parts of Northeast China in January except some areas where it shows a decreasing trend, while in August, it shows an increasing trend in almost all the parts of Northeast China. The temperature change varies greatly among regions; it shows an increasing trend from the southeast to the northwest on the whole, with the largest increment being $2^{\circ} \mathrm{C}$. The temperature increases most obviously in the northern part of Great Khingan Mountains and Lesser Khingan Mountains, while it increases most slightly in Liaohe Plain, Liaodong Peninsula, and the southern part of Changbai Mountains (Figure 3). The temperature rise in these regions is closely related with the land use conversion in the future. For example, the conversion from forests and grasslands into cultivated land in Great Khingan Mountains and Lesser Khingan Mountains leads to the increase of the regional near-surface temperature not only in the regions with land use conversion but also in the regions without land use conversion.
The simulation result indicates that there is not significant change in the annual precipitation in Northeast China during 2030-3040 but there is some fluctuation of the seasonal precipitation. The precipitation will increase most greatly in the middle part of Heilongjiang Province and the eastern part of Jilin Province and Liaoning Province. Besides, the precipitation will increase most significantly in the summer, and it will decrease in some regions in the winter. The precipitation will show a decreasing trend on the whole in January; it will show very different changing trends in different regions in August but still show a decreasing trend on the whole. The precipitation will decrease by $80 \mathrm{~mm}$ on average in January, with the largest decrement reaching $120 \mathrm{~mm}$. By comparison, it will change more significantly in August (Figure 4). The precipitation will decrease most greatly in Liaodong Peninsula and the southern part of Changbai Mountains, while it will obviously increase in the northern part of Great Khingan Mountains and Songnen Plain. In addition, it will show great difference at the local scale during different periods since there are some instabilities in the precipitation.

The previous researches have indicated that the climate change will have significant impacts on the crop yield, and that there is significant regional difference in these impacts [26-28]. When the temperature increases by $1^{\circ} \mathrm{C}$, the per unit area yields of the wheat and soybean may increase by $2 \%-40 \%$, and the decrement is higher in the northeast part than it is in the southwest part of Northeast China. When the precipitation increases by $10 \%$, the grain yield will increase by approximately $10 \%$ in the western and southwest parts, while it is the contrary in the southeast part [29]. However, the temperature rise may aggravate the decrease of precipitation, since they generally appear simultaneously. In addition, the previous researches indicate that when the 


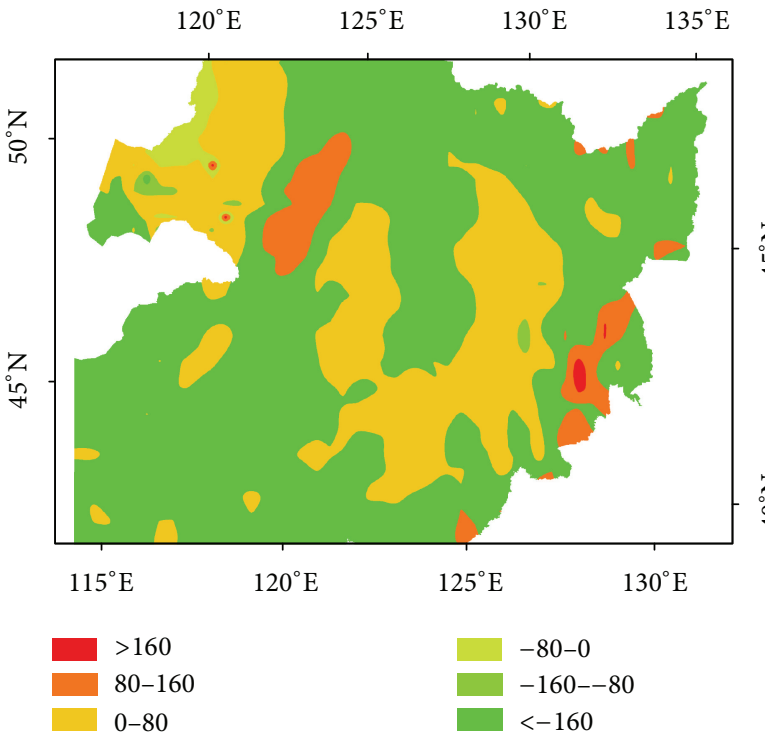

(a)

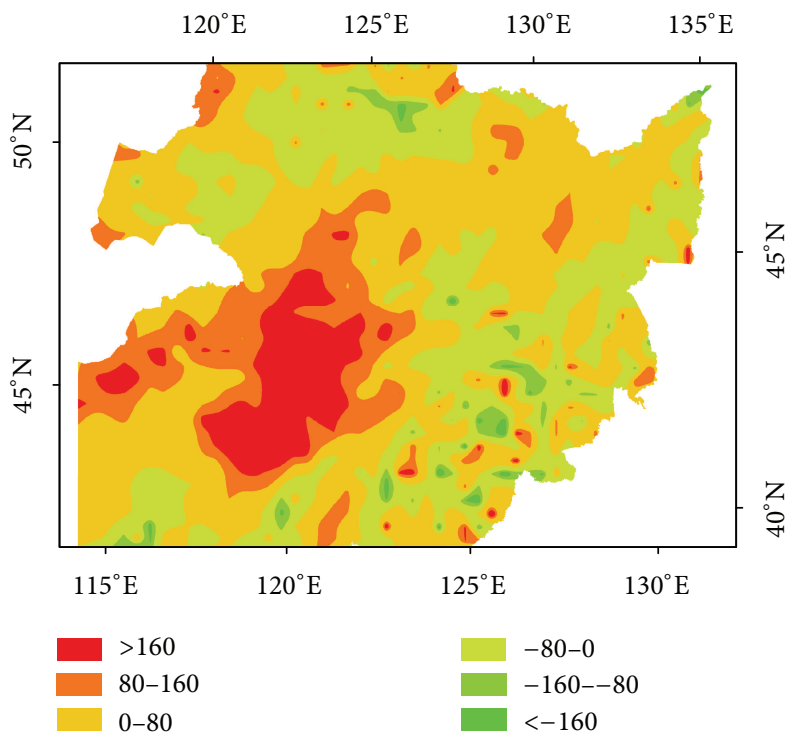

(b)

FIgURE 4: Change of precipitation in Northeast China in DJF (a) and JJA (b) caused by land use/cover change during 2030-2040.

temperature increases by $2^{\circ} \mathrm{C}$ and the precipitation decreases by $20 \%$, the grain yield in the western part of Northeast China will decrease by $10 \%-18 \%$ [30]. Therefore, the future grain yield in Northeast China will show a decreasing trend on the whole, and the grain yield and soybean yield may decrease by at least $10 \%$ in the future.

This study simulated the climatic effects of cultivated land reclamation in Northeast China during 2030-2040 on the basis of the WRF model. The simulation results indicate that it will inevitably aggravate the drought disaster in Northeast China. In summary, the regions with the most extreme temperature change are mainly located in the northern part of Great Khingan Mountains and Lesser Khingan Mountains, while the regions with the significant precipitation change are mainly gathered in the northern parts of Great Khingan Mountains and Songnen Plain. Since these regions are located in the major grain-producing areas in Northeast China, the climate change due to the cultivated land reclamation will have great impacts on the grain yield in Northeast China.

\section{Conclusion and Discussion}

The change of the spatial pattern of land use in Northeast China in the future, mainly including the expansion of cultivated land, will influence the supply function of regional ecosystem services to some degree. It should be noted that although the cultivated land area in Northeast China will show an increasing trend, the population will increase more rapidly, which will lead to the reclamation of some marginal land that is not very suitable for reclamation. Since the rapid population growth will lead to more demand for the food and land resources, some problems such as the deforestation, reclaiming land from lakes, and grassland reclamation may be more serious and lead to a vicious cycle. Besides, some of the newly increased cultivated lands may not be reasonably used, and the extensive operation is still very widespread, which will inevitably lead to the deterioration and waste of the land resources. The decline of soil fertility will undermine the potential of grain yield increase, influence the grain production capacity of Northeast China and subsequently influence the grain production capacity of the whole of China, and consequently threaten the self-supply of grain and national food security. It is necessary to properly implement some measures in the planning of the future agricultural development in Northeast China on the premise of guaranteeing the strategic grain demand of the whole nation. Besides, it is necessary to improve the scientific and technological level of agricultural cultivation, promote the ecological construction, and enhance the land utilization rate. In addition, it is necessary to implement different agricultural production countermeasures according to the impacts of climate change on different crops in different regions, for example, adjusting the layout of crop variety and planting structure and enhancing the measure to prevent disasters so as to ensure the long-term and steady development of grain production.

The temperature will show an increasing trend on the whole, which will have negative impacts on the growth of the major crops such as rice, corn, soybean, and wheat. The regional climate change will also directly and indirectly influence the behaviors of the peasants. For example, it will directly lead to the change of the planting structure and tillage measures; besides, it will lead to the change of the grain yield, indirectly change the income of peasants, and consequently alter their production activities. In addition, since different crops have different adaptive capacities to climate change, this will greatly influence the peasants' choice of the kinds of crops and consequently lead to more serious imbalance in the plantation structure. For example, in the middle and western parts of Northeast China, where the major crop is rice, when 
the temperature increases and the precipitation decreases, the local peasants may replace the rice with other crops or offset the impacts of climate change on the rice by using more fertilizers or irrigating the crops with more water. So, the grain production in Northeast China has some potential to adapt to the temperature rise, and it is of great significance to alleviating the negative impacts of the temperature rise on the grain production and guaranteeing the food security in Northeast China to give full play to this potential.

This study has mainly aimed at the simulation and prediction of the change of temperature and precipitation caused by the cultivated land reclamation in the future. In order to forecast the climate change in the future more accurately, it is necessary to quantitatively analyze the changing trends of the temperature and precipitation and comprehensively take into account the future changes of the monsoon, general atmospheric circulation, change of other land use types, and so forth, in the climate model and data analysis. Therefore, there is still something to explore in the future researches. First, the regional climate change is caused by various factors, including not only the human activities but also the natural factors such as the solar activity. Besides, there are also various human activities that influence the regional climate change in Northeast China, but only the cultivated land reclamation has been taken into account in this study, so, more influencing factors should be included in the future research. Second, there are some uncertainties in the simulation. Due to those influenced factors, the effects of some of them on the climate change may not be captured in the simulation analysis, which will lead to some uncertainties in the simulation results. So, it is necessary to make further sensitivity analysis in the future research so as to make the simulation results more accurate.

\section{Conflict of Interests}

The authors declare that there is no conflict of interests regarding the publication of this paper.

\section{Acknowledgments}

This research was supported by China National Natural Science Funds for Distinguished Young Scholar (Grant no. 71225005) and National Key Programme for Developing Basic Science in China (Grant no. 2010CB950904).

\section{References}

[1] H. Ding and S. Dai, "Temperature variation in China during the last 100 years," Meteorological Monthly, vol. 12, no. 1, pp. 19-26, 1994.

[2] X. Deng, J. Huang, S. Rozelle, and E. Uchida, "Economic growth and the expansion of urban land in China," Urban Studies, vol. 47, no. 4, pp. 813-843, 2010.

[3] Q. Jiang, X. Deng, H. Yan, D. Liu, and R. Qu, "Identification of food security in the mountainous guyuan prefecture of China by exploring changes of food production," Journal of Food, Agriculture \& Environment, vol. 10, no. 1, pp. 210-216, 2012.
[4] X. Deng, J. Huang, F. Qiao et al., "Impacts of El Nino-Southern Oscillation events on China's rice production," Journal of Geographical Sciences, vol. 20, no. 1, pp. 3-16, 2010.

[5] H. Sun, J. Yuan, and S. Lu, "The change and test of climate in Northeast China over the last 100 years," Climatic and Environmental Research, vol. 11, no. 1, pp. 101-108, 2006.

[6] R. Betts, "Implications of land ecosystem-atmosphere interactions for strategies for climate change adaptation and mitigation," Tellus B, vol. 59, no. 3, pp. 602-615, 2007.

[7] J. Liu and X. Deng, "Impacts and mitigation of climate change on Chinese cities," Current Opinion in Environmental Sustainability, vol. 3, no. 3, pp. 188-192, 2011.

[8] R. A. Pielke, A. Pitman, D. Niyogi et al., "Land use/land cover changes and climate: Modeling analysis and observational evidence," Wiley Interdisciplinary Reviews, vol. 2, no. 6, pp. 828850, 2011.

[9] K. J. Anderson and E. DeLucia, "Study finds a better way to gauge the climate costs of land use changes," Nature Climate Change, 2012.

[10] X. Deng, J. Huang, S. Rozelle, and E. Uchida, "Cultivated land conversion and potential agricultural productivity in China," Land Use Policy, vol. 23, no. 4, pp. 372-384, 2006.

[11] S. Donner, "The impact of cropland cover on river nutrient levels in the Mississippi River Basin," Global Ecology and Biogeography, vol. 12, no. 4, pp. 341-355, 2003.

[12] X. Chen, J. Chen, Y. Shi, and Y. Yamaguchi, "An automated approach for updating land cover maps based on integrated change detection and classification methods," ISPRS Journal of Photogrammetry and Remote Sensing, vol. 71, pp. 86-95, 2012.

[13] G. B. Bonan, "Observational evidence for reduction of daily maximum temperature by Croplands in the Midwest United States," Journal of Climate, vol. 14, no. 11, pp. 2430-2442, 2001.

[14] D. B. Lobell, G. Bala, and P. B. Duffy, "Biogeophysical impacts of cropland management changes on climate," Geophysical Research Letters, vol. 33, no. 6, Article ID L06708, 2006.

[15] X. Deng, C. Zhao, and H. Yan, "Systematic modeling of impacts of land use and land cover changes on regional climate: a review," Advances in Meteorology, vol. 2013, Article ID 317678, 11 pages, 2013.

[16] A. T. Peterson, M. A. Ortega-Huerta, J. Bartley et al., "Future projections for Mexican faunas under global climate change scenarios," Nature, vol. 416, no. 6881, pp. 626-629, 2002.

[17] R. G. Pearson and T. P. Dawson, "Predicting the impacts of climate change on the distribution of species: are bioclimate envelope models useful?" Global Ecology and Biogeography, vol. 12, no. 5, pp. 361-371, 2003.

[18] M. B. Araújo and M. New, "Ensemble forecasting of species distributions," Trends in Ecology \& Evolution, vol. 22, no. 1, pp. 42-47, 2007.

[19] J. M. Murphy, D. M. H. Sexton, D. H. Barnett et al., "Quantification of modelling uncertainties in a large ensemble of climate change simulations," Nature, vol. 430, no. 7001, pp. 768-772, 2004.

[20] J. H. Christensen and O. B. Christensen, "A summary of the PRUDENCE model projections of changes in European climate by the end of this century," Climatic Change, vol. 81, no. 1, pp. 730, 2007.

[21] R. J. Hijmans and C. H. Graham, "The ability of climate envelope models to predict the effect of climate change on species distributions," Global Change Biology, vol. 12, no. 12, pp. 22722281, 2006. 
[22] X. Deng, Q. Jiang, J. Zhan, S. He, and Y. Lin, "Simulation on the dynamics of forest area changes in Northeast China," Journal of Geographical Sciences, vol. 20, no. 4, pp. 495-509, 2010.

[23] X. Deng, Q. Jiang, H. Su, and F. Wu, "Trace forest conversions in Northeast China with a 1-km area percentage data model," Journal of Applied Remote Sensing, vol. 4, no. 1, Article ID 041893, 2010.

[24] J. Liu, M. Liu, D. Zhuang, Z. Zhang, and X. Deng, "Study on spatial pattern of land-use change in China during 1995-2000," Science in China D, vol. 46, no. 4, pp. 373-384, 2003.

[25] J. Liu, Z. Zhang, X. Xu et al., "Spatial patterns and driving forces of land use change in China during the early 21st century," Journal of Geographical Sciences, vol. 20, no. 4, pp. 483-494, 2010.

[26] Y. Wang, Y. Lou, and W. Zhang, "Impact of climate warming on crop plant in northeastern of China," Meteorological Science and Technology, vol. 29, pp. 11-13, 2001.

[27] H. Sun, Q. Yang, S. Lu, and Y. Yang, "The contrast analysis on the average and extremum temperatre trend in Northeast China," Journal of the Meteorological Sciences, vol. 26, no. 2, pp. 157-163, 2006.

[28] Z. Deng, Q. Wang, Q. Zhang et al., "Impact of climate warming and drying on food crops in northern China and the countermeasures," Acta Ecologica Sinica, vol. 30, no. 22, pp. 6278-6288, 2010.

[29] Q. Ma, "A simulating study on the influences of climate change on grain yield and the countermeasures in the Northeast China," Acta Meteorologica Sinica, vol. 54, no. 4, pp. 484-492, 1996.

[30] S.-Q. Ma, Q. Wang, and X.-L. Luo, "Effect of climate change on maize (Zea mays) growth and yield based on stage sowing," Acta Ecologica Sinica, vol. 28, no. 5, pp. 2131-2139, 2008. 

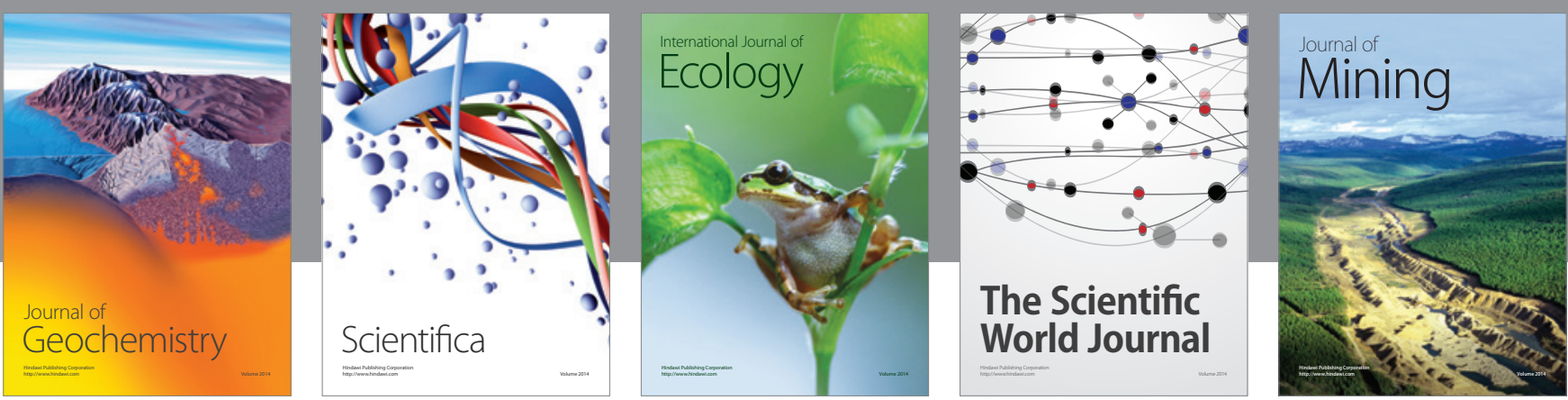

The Scientific World Journal
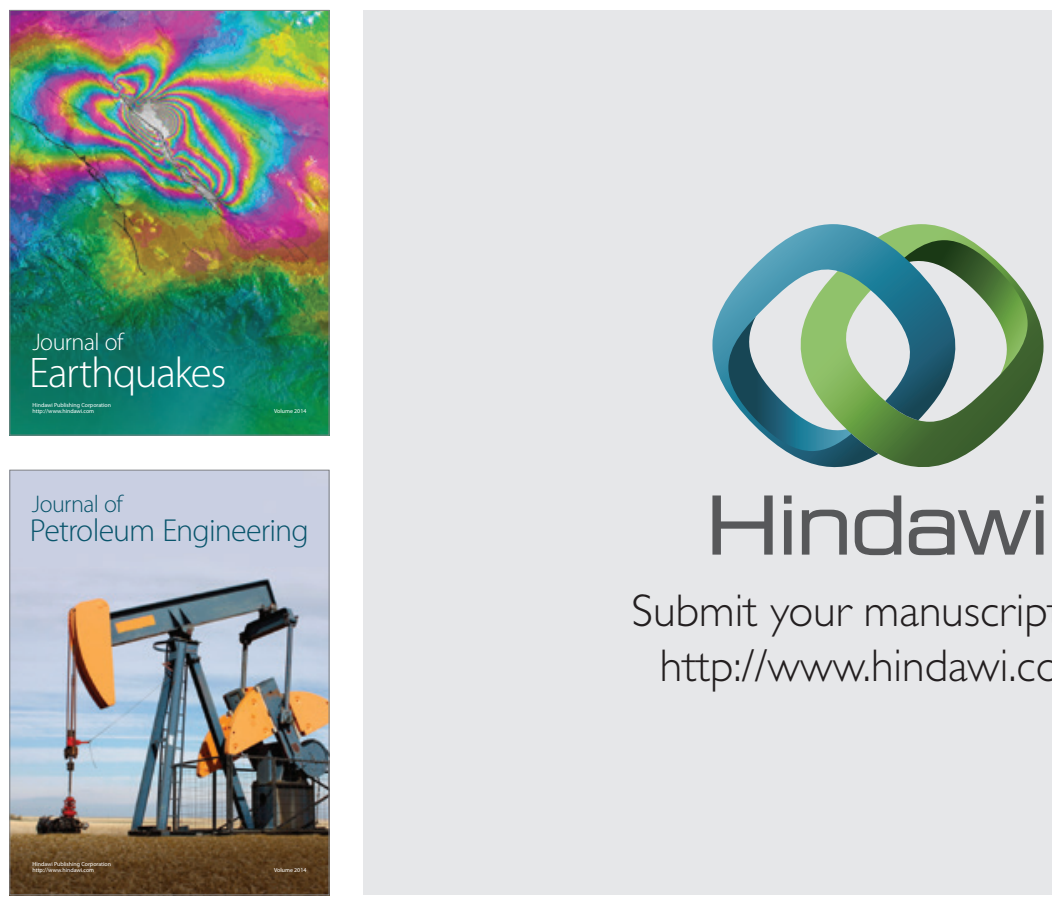

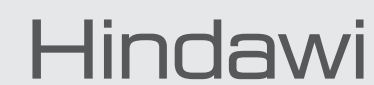

Submit your manuscripts at

http://www.hindawi.com
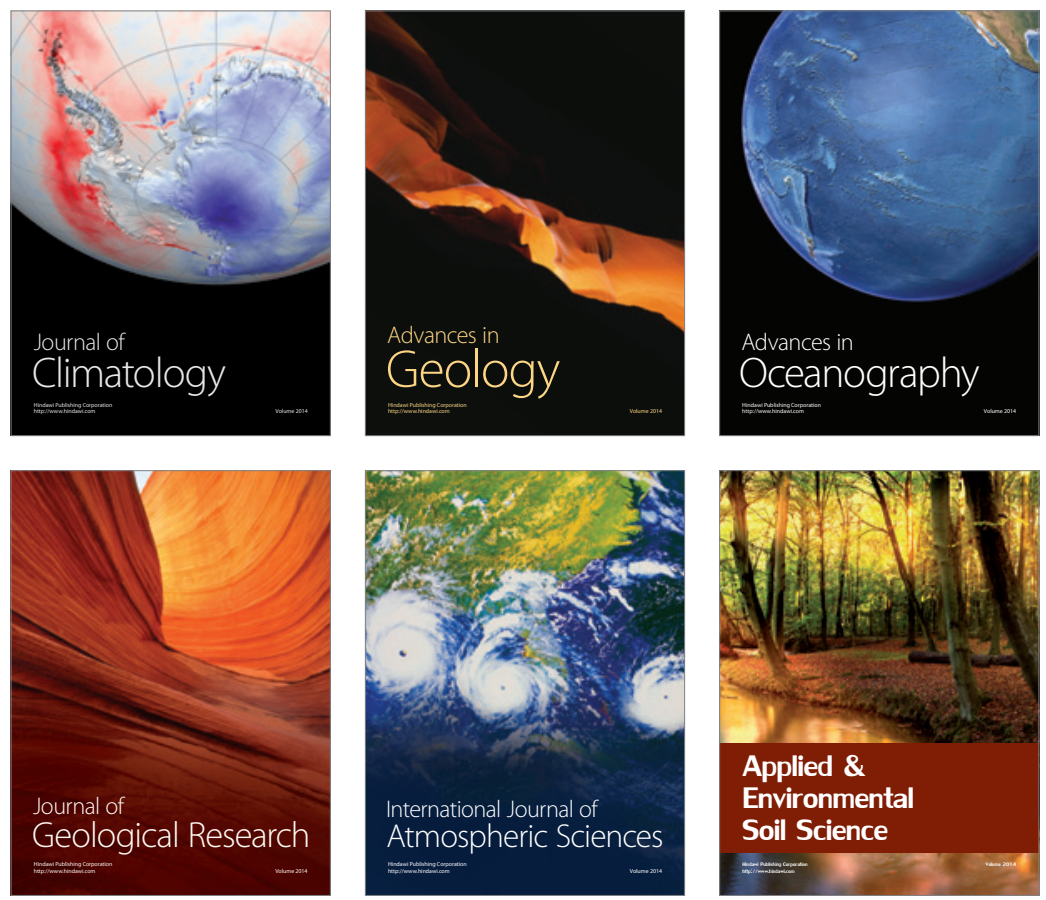
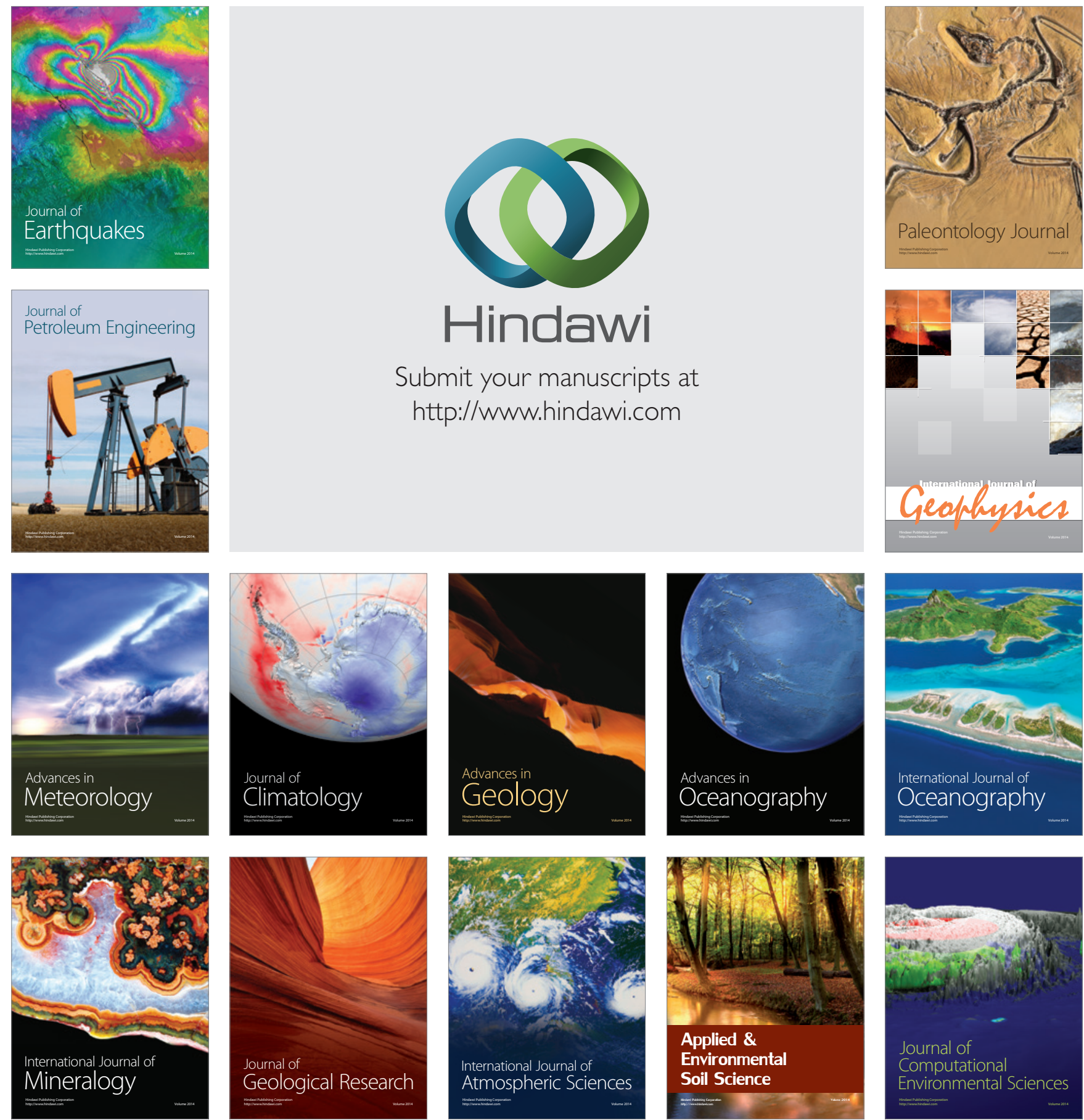